\title{
How can we imagine the future of anti-tumors therapies?
}

Volume I Issue 6 - 2014

\section{Editorial}

Cancer represents one of the biggest challenges facing health professionals and thus, continuous efforts are made toward finding efficient treatments. Furthermore, cancer has heavy impacts on global economy and the drugs coast limits the access to treatment for patients in many developing countries. Herein, the two main therapeutic struggles to overcome are the diversity in cancer types and the post-treatment tumoral re-growth. The second problem could be overcome by a treatment that target the cancer stem cells, which have a self-renewal property, ${ }^{1,2}$ and that have been associated with drug resistance. ${ }^{3,4}$ Different therapies are currently used including radiotherapy, chemotherapy ${ }^{5}$ and surgery. However, none of them has been shown to completely cure the cancer with a zero risk of tumoral re-growth mainly because these methods are not precise and cannot distinguish between the healthy and the tumoral cells.

Fortunately, the current researches indicate that the future will bring new therapeutic approaches especially that pharmacology is investigating divers aspects including cells receptors, ${ }^{6-9}$ neural signaling, ${ }^{10,11}$ biochemical interactions, ${ }^{12,13}$ toxicology ${ }^{14}$ and even traditional medicines. ${ }^{9,10,15,16}$ All that combined with the development of animal models ${ }^{13,17-20}$ to both test drugs and elucidating the pathological pathways. Importantly, immunology constitutes one of the most promising approaches, and developing methods such as specific antibody, immune-agents and immune-modulators ${ }^{21,22}$ may lead to more efficient antitumor efficiency via a more specific immunological targeting along with the use of more selective agents injected at the suitable dosage based on the immunological profile of the cancerous and both the type and the stage of the cancer.

Since some cancers have been linked to some virus, vaccinations are also being considered ${ }^{23,24}$ as preventive approaches. On the other hand, we might take advantages from the cytolytic properties of the virus and inject specific virus at a studied dosage within the tumoral site to kill the tumor cells. In such case we may consider using an antiviral to control the virus effect and protect the healthy cells.

Furthermore, the biochemical and the structural properties are elements on which therapies can be based. Indeed, tumoral cells might express specific molecules that the healthy cells do not express or express differently therefore, specific therapies that target those tumoral-specific molecules such as histone deacetylase ${ }^{25}$ and signal transduction cascades ${ }^{26}$ look promising approaches. The mechanisms of action could be enzymatic inhibition, metabolic disorder and other intracellular approaches or inter-cellular communication disturbance of the tumoral cells. Moreover, acting on the tumormicroenvironment ${ }^{27}$ and create an unbalances within the homeostatic status through targeting the irrigation and the blood supply to the tumoral cells by cryotherapy or surgery represent another approach.

Finally, stem cells transplantations may be used within the cancer therapies ${ }^{28,29}$ or as a way to modulate the immune system activity by replacing some missing elements or by strengthening the activities

\author{
Abdelaziz Ghanemi, 1,2 \\ 'Key Laboratory of Animal Models and Human Disease \\ Mechanisms of Chinese Academy of Sciences \& Yunnan Province, \\ Kunming Institute of Zoology, China \\ ${ }^{2}$ University of Chinese Academy of Sciences, China
}

Correspondence: Abdelaziz Ghanemi, Kunming Institute of Zoology Chinese Academy of Sciences No.32 Jiaochang Donglu, Kunming 65223, Yunnan Province, China, Email ghanemiabdelaziz@hotmail.com

Received: October 13, 2014 | Published: October 15, 2014

the immune system already has. Following this line of thoughts gene therapy could be combined to the stem cells transplantations to provide the transplanted cells with novel properties via the introduced genes.

The best therapeutic approaches we could imagine might be combining two or more therapies that would be selected based on the cancer type, cancer stage, patient pathological and physiological profile and even both the ethnic group and the gender of the patients. ${ }^{30}$ However, we still have a very long way before oncologists can evoke a victory against cancer and thus collaborative efforts still required to reach specific and precise therapies with less side effects.

\section{Acknowledgments}

Abdelaziz GHANEMI is a recipient of a 2013 CAS-TWAS President's Postgraduate Fellowship.

\section{Conflicts of interest}

None.

\section{References}

1. Xing F, Wu K, Watabe K. MicroRNAs in Cancer Stem Cells: New Regulators of Stemness. Curr Pharm Des. 2014;20(33):5319-5327.

2. Gu MJ, Jang BI. Jang Clinicopathologic Significance of Sox2, CD44 and CD44v6 Expression in Intrahepatic Cholangiocarcinoma. Pathol Oncol Res. 2014;20(3):655-660.

3. Gong Y, Wang J, Huo L, et al. Aldehyde Dehydrogenase 1 Expression in Inflammatory Breast Cancer as Measured by Immunohistochemical Staining. Clin Breast Cancer. 2014;14(3):e81-e88.

4. Li Y, Zhang T. Targeting cancer stem cells by curcumin and clinical applications. Cancer Lett. 2014;346(2):197-205.

5. Maggiore RJ, Curran EK, Witt ME, et al. Survival and selected outcomes of older adults with locally advanced head/neck cancer treated with chemoradiation therapy. J Geriatr Oncol. 2013;4(4):327-333. 
6. Ghanemi A, He L, Yan M. New factors influencing G protein coupled receptors' system functions. Alexandria Journal of Medicine. 2013;49(1):1-5

7. Ghanemi A. Targeting G protein coupled receptors-related pathways as emerging molecular therapies. Saudi Pharmaceutical Journal. 2013;doi:10.1016/j.jsps.2013.07.007.

8. Ghanemi A. Cell cultures in drug development: Applications, challenges and limitations. Saudi Pharmaceutical Journal. 2014;doi:10.1016/j. jsps.2014.04.002.

9. Ghanemi A, Hu X. Targeting the orexinergic system: Mainly but not only for sleep-wakefulness therapies. Alexandria Journal of Medicine. 2014; doi:10.1016/j.ajme.2014.07.002.

10. Ghanemi A. How important is pharmacognosy for doctors and dentists? The Saudi Dental Journal. 2014;doi:10.1016/j.sdentj.2014.08.002.

11. Ghanemi A. Schizophrenia and Parkinson's disease: Selected therapeutic advances beyond the dopaminergic etiologies. Alexandria Journal of Medicine. 2013;49(4):1-5.

12. Ghanemi A. Biological properties and perspective applications of "Bioneuter" chemicals? Saudi Pharm J. 2014;22(1):1-2.

13. Ghanemi A. Animal models of Alzheimer's disease: Limits and challenges. NPG Neurologie - Psychiatrie-Geriatrie. 2014;14(84):303305 .

14. Ghanemi A. How to define a pharmacological or a toxic food? Alexandria Journal of Medicine. 2014; doi:10.1016/j.ajme.2014.06.004.

15. Ghanemi A. Is mapping borders between pharmacology and toxicology a necessity? Saudi Pharmaceutical Journal. 2014;doi:10.1016/j. jsps.2014.03.001.

16. Boubertakh B, Liu XG, Cheng XL, Li P. A Spotlight on Chemical Constituents and Pharmacological Activities of Nigella glandulifera Freyn et Sint Seeds. Journal of Chemistry. 2013;2013(2013):1-12.

17. Khorramizadeh MR, Saadat F. Chapter 8-Animal Models for Human Disease. In: Singh ASV (Ed.), Animal Biotechnology. Academic Press, San Diego, USA. 2014;pp.139-154.

18. Welsh J. Chapter 40 - Animal Models for Studying Prevention and Treatment of Breast Cancer. Conn PM (Ed.), Animal Models for the Study of Human Disease. Academic Press, Boston, USA. 2013;pp.9971018 .
19. Berman JN, Chiu PPL, Dellaire G. Chapter 8 - Preclinical Animal Models for Cancer Genomics. In: Arceci GDNBJ (Ed.), Cancer Genomics. Academic Press, Boston, USA. 2014;pp.109-131.

20. Ghanemi A. Are we in Need of Dividing Zoology into Two Fields? J Dairy Vet Anim Res. 2014;1(1):1-2.

21. Sideras K, Braat H, Kwekkeboom J, et al. Role of the immune system in pancreatic cancer progression and immune modulating treatment strategies. Cancer Treat Rev. 2014;40(4):513-522.

22. Harper J, Sainson RC. Regulation of the anti-tumour immune response by cancer-associated fibroblasts. Semin Cancer Biol. 2014;25:69-77.

23. Felskov BB, Dehlendorff C, Munk C, et al. Early Impact of Human Papillomavirus Vaccination on Cervical Neoplasia-Nationwide Followup of Young Danish Women. J Natl Cancer Inst. 2014;106(3):460.

24. Gravekamp C, Jahangir A. Is cancer vaccination feasible at older age? Exp Gerontol. 2014;54:138-144.

25. Feng W, Zhang B, Cai D, et al. Therapeutic potential of histone deacetylase inhibitors in pancreatic cancer. Cancer Lett. 2014;347(2):183-190.

26. Shrimali D, Shanmugam MK, Kumar AP, et al. Targeted abrogation of diverse signal transduction cascades by emodin for the treatment of inflammatory disorders and cancer. Cancer Lett. 2013;341(2):139-149.

27. Wood SL, Pernemalm M, Crosbie PA, et al. The role of the tumormicroenvironment in lung cancer-metastasis and its relationship to potential therapeutic targets. Cancer Treat Rev. 2014;40(4):558-566.

28. Muller AM, Kohrt HE, Cha S, et al. Long-term outcome of patients with metastatic breast cancer treated with high-dose chemotherapy and transplantation of purified autologous hematopoietic stem cells. Biol Blood Marrow Transplant. 2012;18(1):125-133.

29. Conrad R, Remberger M, Cederlund K, et al. Inflammatory cytokines predominate in cases of tumor regression after hematopoietic stem cell transplantation for solid cancer. Biol Blood Marrow Transplant. 2006;12(3):346-354.

30. Lim WY, Tan CS, Loy EY, et al. Lung cancer incidence in Singapore: Ethnic and gender differences. Lung Cancer. 2014;84(1):23-30. 